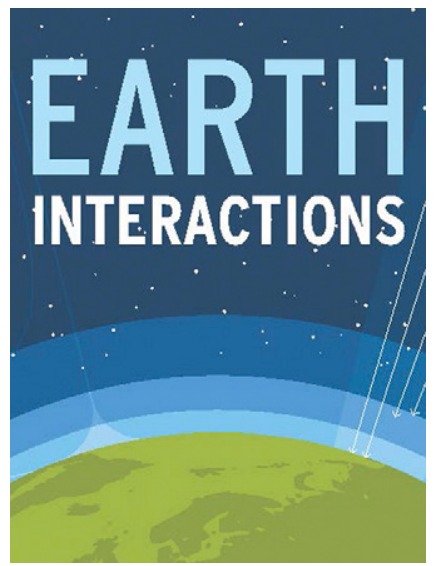

Copyright @ 2014, Paper 18-014; 59110 words, 14 Figures, 0 Animations, 0 Tables.

http://EarthInteractions.org

\title{
Hydroclimate Variability and Change in the Prairie Pothole Region, the "Duck Factory" of North America*
}

\section{Tristan Ballard, ${ }^{+}$Richard Seager, ${ }^{\#, @ ~ J a s o n ~ E . ~ S m e r d o n, ~}{ }^{\#}$ Benjamin I. Cook, ${ }^{\text {\& }}$ Andrea J. Ray, ${ }^{* *}$ Balaji Rajagopalan, ${ }^{++}$ Yochanan Kushnir," Jennifer Nakamura," and Naomi Henderson ${ }^{\#}$}

${ }^{+}$Duke University, Durham, North Carolina

\# Lamont Doherty Earth Observatory, Columbia University, Palisades, New York

\& NASA Goddard Institute for Space Studies, New York, New York

** NOAA/Earth System Research Laboratory, Boulder, Colorado

${ }^{++}$Department of Civil, Environmental and Architectural Engineering, University of Colorado, Boulder, Colorado

Received 3 January 2014; accepted 28 April 2014

ABSTRACT: The Prairie Pothole Region (PPR) of the northern Great Plains is a vital ecosystem responsible each year for producing $50 \%-80 \%$ of new recruits to the North American duck population. Climate variability and change can impact the hydrology and ecology of the region with implications for waterfowl populations. The historical relationship between PPR wetlands, duck

* Lamont Doherty Earth Observatory Contribution Number 7818.

${ }^{\circledR}$ Corresponding author address: Richard Seager, Lamont Doherty Earth Observatory of Columbia University, 61 Route 9W, Palisades, NY 10964.

E-mail address: seager@ldeo.columbia.edu 
Earth Interactions - Volume 18 (2014) • Paper No. 14 • Page 2

populations, and seasonal hydroclimate are explored. Model experiments from phase 5 of the Coupled Model Intercomparison Project are used to determine whether a recent wetting trend is due to natural variability or changing climate and how PPR hydroclimate will change into the future. Year-to-year variations in May duck populations, pond numbers, and the Palmer drought severity index are well correlated over past decades. Pond and duck numbers tend to increase in spring following La Niña events, but the correlation is not strong. Model simulations suggest that the strengthening of the precipitation gradient across the PPR over the past century is predominantly due to natural variability and therefore could reverse. Model projections of future climate indicate precipitation will increase across the PPR in all seasons except summer, but this gain for surface moisture is largely offset by increased evapotranspiration because of higher temperatures and increased atmospheric evaporative demand. In summer, the combined effects of warming and precipitation changes indicate seasonal surface drying in the future. The presented hydroclimate analyses produce potential inputs to ecological and hydrological simulations of PPR wetlands to inform risk analysis of how this North American waterfowl habitat will evolve in the future, providing guidance to land managers facing conservation decisions.

KEYWORDS: North America; Climate change; Hydrologic cycle; Climate variability; Ecosystem effects

\section{Introduction}

The Prairie Pothole Region (PPR) contains between 5 and 8 million wetland basins in small depressions left behind by the most recent Pleistocene glaciation. The PPR provides immense biological and ecosystem services to our society (Johnson et al. 2010). First and foremost, the region acts as an ideal waterfowl breeding habitat, producing 50\%-80\% of North American ducks in late spring and summer (Batt et al. 1989). This $800000 \mathrm{~km}^{2}$ region spans five states (Montana, North Dakota, South Dakota, Iowa, and Minnesota) and three Canadian provinces (Manitoba, Saskatchewan, and Alberta) (Batt et al. 1989). Besides being the "duck factory" of North America and "the single most productive habitat for waterfowl in the world" (Johnson et al. 2005), the PPR is also an important habitat for insects, amphibians, and other migratory birds (Sorenson et al. 1998). The PPR has economic implications as well. In 2006, expenditures by an estimated 1.3 million waterfowl hunters in the United States totaled over $\$ 900$ million, supporting over 27000 jobs (Carver 2006). Additionally, wetland restoration is an option for carbon sequestration projects, with restoration in the Canadian PPR having a sequestration potential of $3.25 \mathrm{Mg} \mathrm{CO}_{2}$ eq ha ${ }^{1} \mathrm{yr}^{1}$ (Badiou et al. 2011).

The PPR, like many other wetlands, has been severely degraded and is one of the most threatened ecosystems in North America (Badiou et al. 2011). Drainage of the potholes first occurred when Europeans settled the area in the late nineteenth century in order to make the land more viable for crop production and ease maneuverability constraints on large machinery (Johnson et al. 2008; Johnston 2013). In the United States, every PPR state has lost over a quarter of its original wetlands, with Minnesota and Iowa the most affected, having less than $15 \%$ of their original wetlands (Johnson et al. 2008; Dahl 1990). Recognizing the damaging effects of drainage on wildlife, the 1985 Food Security Act and subsequent farm bills 
included a provision referred to as "Swampbuster," which greatly restricts future tillage projects (Gleason et al. 2011). Monitoring and enforcement of the rules have not been vigorous, however, and demand for biofuels is renewing interest in agricultural development (Johnson et al. 2008; Johnston 2013). Additionally, PPR potholes are important carbon sinks, and drainage of wetlands leads to rapid releases of $\mathrm{CO}_{2}$ to the atmosphere (Badiou et al. 2011). Furthermore, the recent surge in oil and gas extraction from the Bakken formation has led to concerns over wetland groundwater contamination as well (Preston et al. 2014). Given the above considerations and the long list of stakeholders that they involve, including conservationists, hunters, homeowners, farmers, local municipalities, and the waterfowl themselves, the future of the PPR, its dependence on climate, and the expected impacts of climate change on the region require a detailed investigation.

The response of wetland habitat to climate variation can be complex, and the PPR may also be quite sensitive to future changes in precipitation and temperature. Prairie pothole wetlands go through a so-called vegetation cover cycle whereby ponds within the basin go from extensive open water with little surrounding vegetation during wet years to little open water surrounded by extensive marsh and emergent cover in drier years. This cycle of plant turnover helps to maintain biodiversity and recycle nutrients (Johnson et al. 2010). Areas in the wetter east of the PPR tend to have long cover cycles and longer sustained high water levels that are, nonetheless, less rich in waterfowl while areas in the drier west of the PPR can often persist in the dry stage and be equally unproductive. Ideal conditions for waterfowl breeding appear to have relatively short cover cycles that exists somewhere in between these two end members. Analyses using weather station data have shown that, over the past century, the zonal precipitation gradient across the PPR has steepened as precipitation has increased in the southeastern part of the PPR and less so or even declined in the northwestern part, shifting optimal waterfowl habitat east (Millett et al. 2009). It is in the east, however, that a higher proportion of wetlands have been drained for farming and where such pressures continue to create challenges for managers who seek to protect and maintain habitat.

Some previous studies have attempted to determine the impacts of future climate change on the PPR but, to date, none have used projections from the most recent climate model projections. Sorenson et al. (1998) used warming scenarios based on a previous generation of climate model projections in regression and wetland simulation models to analyze future change. They predicted over a $50 \%$ reduction in ponds and duck populations by 2060. More recent studies (Johnson et al. 2005, 2010) did not use climate model projections but instead used idealized climate scenarios with temporally and spatially uniform imposed temperature and precipitation changes to drive wetland models. These studies indicate that warming alone would tend to make the wetter eastern regions more favorable for waterfowl as cover cycles shorten. Farther west, significant increases in precipitation will be required to match the increased evaporative demand of a warmer climate, threatening the current westward extent of the PPR wetlands (Larson 1995; Sorenson et al. 1998; Johnson et al. 2005).

Given the limitations of these studies, there remain significant knowledge gaps regarding hydroclimate variability and change in the PPR. The most recent studies, 
Earth Interactions - Volume 18 (2014) • Paper No. 14 • Page 4

while conducting detailed wetlands simulations, only looked at the response to changes in temperature and precipitation that were spatially and temporally uniform rather than actual projections of climate models. Climate change will nevertheless vary spatially and by season, and ducks make use of the wetlands on a seasonal basis. These considerations motivate the current study, which provides the following:

(i) a detailed analysis of the changes in seasonal precipitation over past decades - in particular the trend to wetter conditions - and an assessment of whether they has been caused by natural climate variability or humandriven climate change and

(ii) the first detailed seasonal analyses of projections of hydroclimate in the PPR using the latest simulations from phase 5 of the Coupled Model Intercomparison Project Phase (CMIP5) performed in conjunction with the Intergovernmental Panel on Climate Change (IPCC) Fifth Assessment Report.

Consequently, this current study is the first attempt to incorporate the CMIP5 simulations into our understanding of impacts on the PPR, analyzing both past hydroclimate variability and future hydroclimate change on a seasonally and spatially varying basis. This sets aside the problem of the complex response of wetlands to climate change and effectively considers just the atmospheric driver of variability and change in the PPR.

We present trends and variability assessments for a suite of climate variables (temperature, precipitation, and Palmer drought severity index) from the twentieth century and relate them to both duck populations and pond counts. We show that there are decadal shifts in pond numbers that correlate with a shift to wetter conditions in the mid-1990s. We then consider whether interannual and decadal signals, such as the El Niño-Southern Oscillation (ENSO) or the Pacific decadal oscillation, are the drivers of climate in the region. Whether there are sources of predictability is important to land managers and wildlife biologists hoping to make predictions in the next year and beyond. We therefore will analyze whether the recent wet trend is due to natural variability or may be attributed to the rise in greenhouse gases, an important assessment regarding predictability in the region. Additionally, we will analyze climate model projections of changes in hydroclimate in the PPR region through the mid-twenty-first century, which has not been done since 1998 (Sorenson et al. 1998).

\section{Data and methods}

Climate and its variability in the PPR vary significantly in space. The northwest PPR is generally cooler and drier, whereas the southeast PPR is generally warmer and wetter. Consequently, the PPR was separated into two regions for analysis: the northwest and the southeast (Figure 1). The northwest PPR contains most of the region in Canada and extends into Montana while the southeast PPR contains most of the region in the United States and the additional Canadian region in Manitoba. The specific boundary between the northwest and southeast PPR corresponds to the strata boundaries used in aerial surveys (see below) and also divides the PPR into roughly equally sized regions. 


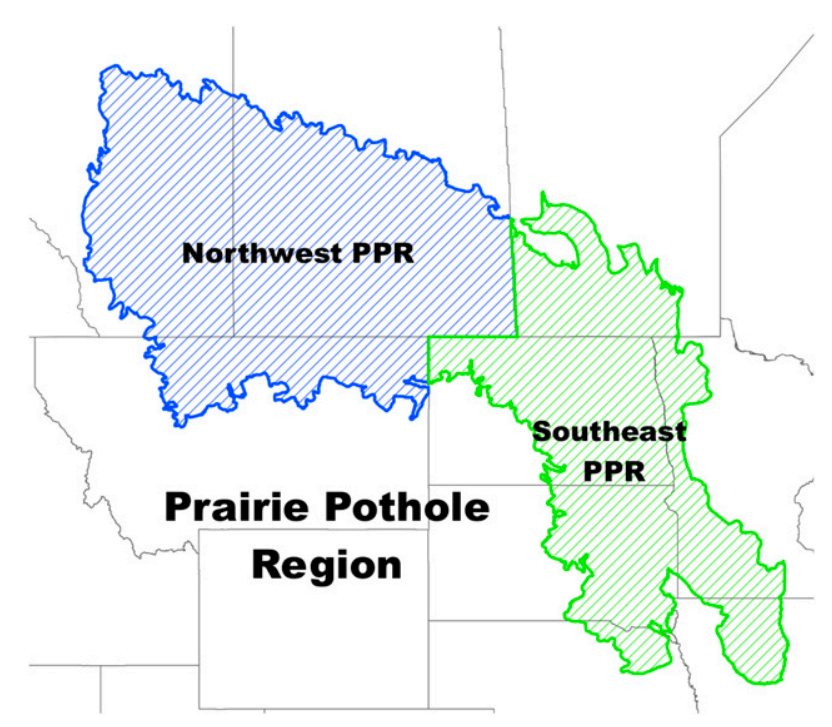

Figure 1. The Prairie Pothole Region showing the northwest region, occupying parts of Alberta and Saskatchewan in Canada and part of Montana in the United States, and the southeast region, occupying parts of North Dakota, South Dakota, Nebraska, Minnesota, and lowa in the United States.

The Waterfowl Breeding Population and Habitat Survey, conducted each May by the Canadian Wildlife Service and the U.S. Fish and Wildlife Service, estimates various duck populations and habitat conditions across much of Canada and the northern United States (the method is described in USFWS/CWS 1987), as seen in Figure 2 (which is taken from https://migbirdapps.fws.gov/mbdc/ databases/mas/WBPHS_2010_strata_map.pdf). Surveys are conducted via lowflying planes, recording not only the number and species of ducks but also the number of water bodies crossed by the plane's transect (Smith 1995). Water bodies that are likely to contain water into the summer are included in the aerial survey, such as type III, IV, and V wetlands, representing seasonal, semipermanent, and permanent basins, respectively, as well as streams, rivers, and artificial water basins (Shaw and Fredine 1956). These water bodies, referred to as May ponds, are used as the primary measurement of waterfowl habitat quantity and quality (Batt et al. 1989).

The aerial surveys began in the PPR region in 1955, but a visibility correction factor for the number of ponds was not integrated until 1974. We therefore use duck populations from 1955 to 2012 and May ponds counts from 1974 to 2012 (Smith 1995). Twelve duck species ${ }^{1}$ are included in the analysis as an estimate for

\footnotetext{
${ }^{1}$ The 12 species in the total duck counts are as follows: American coot Fulica americana, American widgeon Anas americana, blue-winged teal Anas discors, canvasback Aythya valisineria, gadwall Anas strepera, green-winged teal Anas crecca, mallard Anas platyrhynchos, northern pintail Anas acuta, northern shoveler Anas clypeata, redhead Aythya americana, ruddy duck Oxyura jamaicensus, and lesser scaup Aythya affinis.
} 


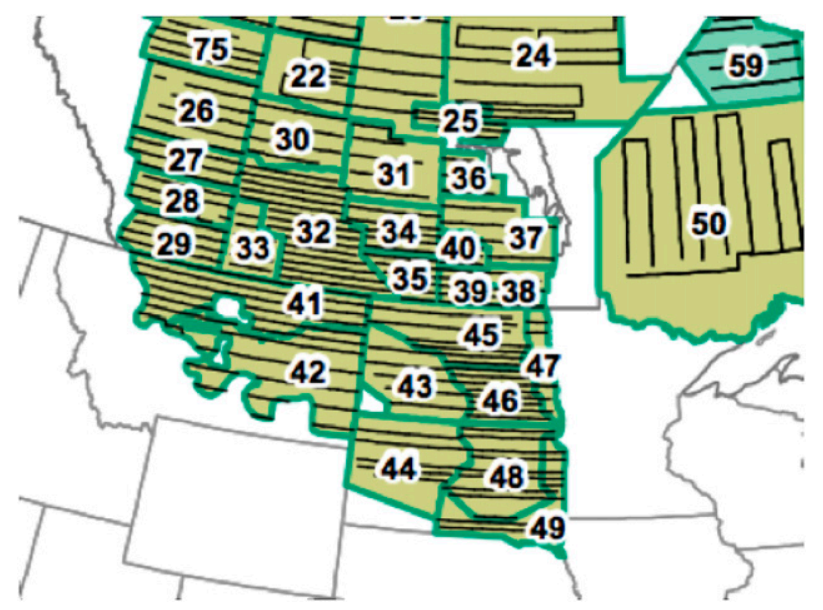

Figure 2. Strata (numbers) and transects (lines) from the annual survey of breeding waterfowl. The northwest region includes strata 26-35 and 41 and the southeast region includes strata $38-40$ and $45-49$. Figure from the U.S. Fish and Wildlife Service.

the total number of ducks in the PPR. The aerial surveys are separated into several geographic strata (Figure 2), and estimates of total ducks and ponds within each strata are calculated based on the survey results (Smith 1995). Strata within the defined northwest PPR and southeast PPR regions were averaged to yield a single annual value for both the total duck population and May pond counts within each region. However, it should be noted that the survey does not include portions of the southeast PPR in Minnesota and Iowa where few wetlands remain.

Monthly climate data, with the exception of the Palmer drought severity index (PDSI), were averaged into four seasons: winter (December-February), spring (March-May), summer (June-August), and fall (September-November). Monthly precipitation rates were obtained from the Global Precipitation Climatology Centre (GPCC) analysis (Schneider et al. 2011), surface temperature is from the Climatic Research Unit (CRU) of the University of East Anglia (Harris et al. 2014), selfcalibrating PDSI is based on the CRU time-series (TS) 3.10.01 datasets from van der Schrier et al. (2013), and sea surface temperature anomalies are from Kaplan et al. (1998).

Future precipitation, temperature, and precipitation minus evapotranspiration were analyzed using 37 radiatively forced climate models from CMIP5. We analyze the projections that were forced with the representative concentration pathway 8.5 (RCP8.5) emissions scenario that assumes an $8.5 \mathrm{~W} \mathrm{~m}^{-2}$ increase in radiative forcing by 2100 because of rising greenhouse gas concentrations. This is CMIP5's high-end emissions scenario [the high-end scenario for CMIP3 was Special Report on Emission Scenarios (SRES) A2] and was chosen to reflect the absence of any international agreement to limit greenhouse gas emissions. Simulations of the historical period from 41 models forced by known and estimated changes in greenhouse gases, solar irradiance, volcanism, aerosols, and land-use changes were 
Earth Interactions - Volume 18 (2014) • Paper No. 14 • Page 7

also analyzed. ${ }^{2}$ Every model simulation in the CMIP5 archive was begun with different initial conditions and hence contains a different sequence of internally generated weather variability that is uncorrelated with the variability in all the other simulations with the same and other models. In contrast, for a given emissions scenario, all the simulations are forced by exactly the same sequence of trace gas radiative forcing and, with some differences, changes in natural (e.g., volcanic) and anthropogenic aerosols. Hence, by averaging over all the model simulations, the variability due to weather is greatly diminished, leaving behind the climate response to the common radiative forcing in the multimodel ensemble mean. Here we analyzed one run per model, which weights the models equally.

\section{Climatological seasonal cycle of precipitation and surface air temperature across the PPR and its representation in climate models}

Before considering hydroclimate variability and change, we begin by looking at the seasonal cycle of precipitation and surface air temperature in the PPR region

\footnotetext{
${ }^{2}$ The models used for the historical period were as follows: Australian Community Climate and Earth-System Simulator, version 1.0 (ACCESS1.0); ACCESS1.3; Beijing Climate Center, Climate System Model, version 1.1 (moderate resolution) [BCC_CSM1.1(m)]; BCC_CSM1.1; Beijing Normal University-Earth System Model (BNU-ESM); Second Generation Canadian Earth System Model (CanESM2); Community Climate System Model, version 4 (CCSM4); Community Earth System Model, version 1-Biogeochemistry (CESM1-BGC); CESM1 (Community Atmosphere Model, version 5) [CESM1(CAM5) FV2]; CESM1-CAM5; CESM1 (with superfast chemistry) (CESM1FASTCHEM); CESM1-Whole Atmosphere Community Climate Model (CESM1-WACCM); Centro Euro-Mediterraneo per I Cambiamenti Climatici Earth System Model (CMCC-ESM); CMCC Climate Model (CMCC-CM); CMCC-CM, with a well-resolved stratosphere (CMCC-CMS); Centre National de Recherches Météorologiques Coupled Global Climate Model, version 5 (CNRM-CM5); Commonwealth Scientific and Industrial Research Organisation Mark, version 3.6.0 (CSIRO Mk3.6.0); Flexible Global Ocean-Atmosphere-Land System Model, gridpoint version 2 (FGOALSg2); Flexible Global Ocean-Atmosphere-Land System Model, second spectral version (FGOALSs2); First Institute of Oceanography (FIO) Earth System Model (FIO-ESM); Geophysical Fluid Dynamics Laboratory Climate Model, version 3 (GFDL CM3); GFDL Earth System Model with Generalized Ocean Layer Dynamics (GOLD) component (GFDL-ESM2G); GFDL-ESM with Modular Ocean Model, version 4 (MOM4) component (GFDL-ESM2M); Goddard Institute for Space Studies Model E2, coupled with Hybrid Coordinate Ocean Model (GISS-E2-H); GISS Model E2, coupled with the Russell ocean model (GISS-E2-R); Hadley Centre Coupled Model, version 3 (HadCM3); Hadley Centre Global Environment Model, version 2-Carbon Cycle (HadGEM2-CC); HadGEM2-Earth System (HadGEM2-ES); Institute of Numerical Mathematics Coupled Model, version 4 (INM-CM4); L'Institut Pierre-Simon Laplace Coupled Model, version 5A, low resolution (IPSL-CM5A-LR); IPSL-CM5A, mid resolution (IPSL-CM5A-MR); IPSL-CM5B-LR; Model for Interdisciplinary Research on Climate, version 5 (MIROC5); MIROC Earth System Model, Chemistry Coupled (MIROC-ESM-CHEM); MIROC-ESM; Max Planck Institute Earth System Model, low resolution (MPI-ESM-LR); MPI-ESM, medium resolution (MPI-ESM-MR); MPI-ESM, paleo (MPIESM-P); Meteorological Research Institute Coupled Atmosphere-Ocean General Circulation Model, version 3 (MRI-CGCM3); Norwegian Earth System Model, version 1 (intermediate resolution) with carbon cycling (NorESM1-ME); and NorESM1-M. For the projections the same models minus CESM1(CAM5.1-FV2), CESM1(FASTCHEM), HadCM3 and MPI-ESM-P were used. This constituted all the models for which the needed data were available at the time the study started.
} 


\section{Climatology Observed (solid), CMIP5 Mean (dashed), CMIP5 (grey)}
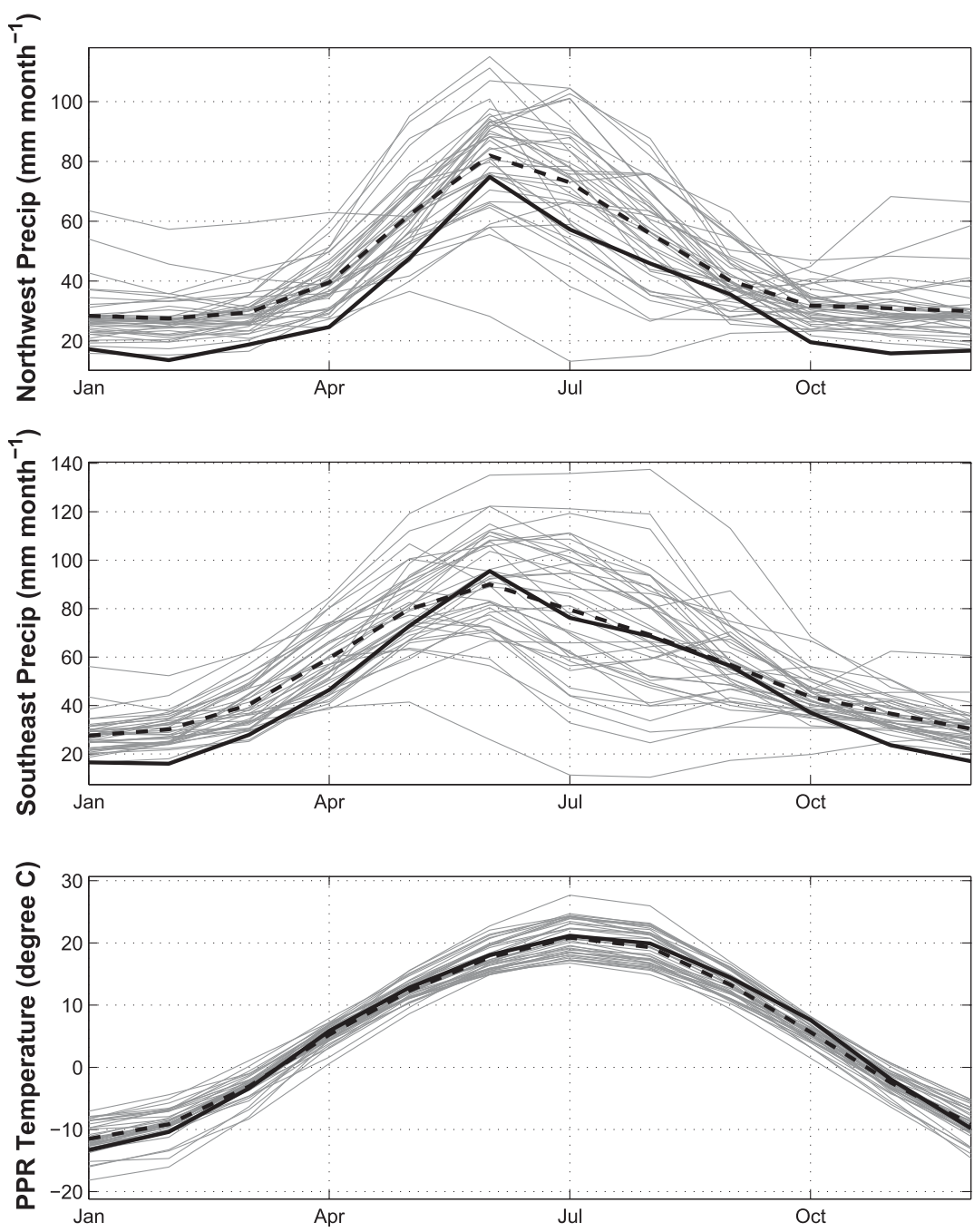

Figure 3. The climatological seasonal cycles of precipitation for (top) the northwest PPR and (middle) the southeast PPR and (bottom) temperature for the entire PPR. The observations are shown as a solid black line and the individual model historical simulations as gray lines with the multimodel mean shown by the thick dashed line. Units are millimeters per month for precipitation and degrees Celsius for temperature.

(Figure 3). For both the northwest and the southeast PPR, the observed precipitation has a clear seasonal cycle with a maximum in June and with the southeast being wetter than the northwest. Figure 3 also shows the climatological seasonal cycles from the historical simulations of all of the models analyzed. Most of the models reproduce this seasonal cycle well, although there are a handful of notably erroneous models. The multimodel mean, shown as a dark dashed line, is very realistic, albeit with a modest wet bias. Temperature is less variable than 
Earth Interactions - Volume 18 (2014) • Paper No. 14 • Page 9

precipitation across the PPR and hence this is shown for an all-PPR average and shows a simple seasonal cycle with a maximum in July. This temperature seasonal cycle is very well reproduced in the historical simulations with the models and with considerable model agreement. Because we will be using CMIP5 climate models to assess the role of climate change in observed PPR hydroclimate history to date and for projections of the future, this level of agreement between models and observations is encouraging. A detailed analysis of the CMIP5 moisture budgets over North America and a comparison to that in the Interim European Centre for Medium-Range Weather Forecasts Re-Analysis can be found in Seager et al. (2014) and again shows reasonable model fidelity in the simulation of the moisture budget, and its relation to atmospheric circulation, in the region.

\section{Precipitation and temperature history in the PPR over the past century}

Figure 4 shows precipitation histories of the northwest and southeast PPR subregions for each season using the entire history of the GPCC data from 1901 to 2010. Interannual to multidecadal variability of precipitation is clearly evident in all seasons with the strongest amplitude of variation occurring in the summer. It is also clear that variations are not consistent across the PPR. For example, in winter [December-February (DJF)], the overall wet period in the 1960s and 1970s in the northwest was not evident in the southeast. In terms of changes over recent decades, precipitation over the northwest PPR has reduced and over the southeast PPR has modestly increased in winter, while there has been a notable wetting trend over the southeast PPR in spring. The southeast PPR has also seen increasing precipitation in fall. In preparation for the discussion to follow, note that there was a widespread (though not unprecedented) drought in the late 1980s to around 1990, which is especially obvious in the southeast PPR. Temperature variability was highly correlated between the northwest and southeast PPR; hence, in Figure 5 we show the temperature histories by season for the entire PPR. Most striking are the post-1980s winter warming, the secular warming in spring to a maximum in the 1980s and some cooling subsequently, and the cool summers in the first two decades of the twentieth century.

\section{Relationships over past decades between climate, pond numbers, and duck populations in the Prairie Pothole Region}

To motivate the remainder of this paper, which is focused on hydroclimate variability and change in the PPR, we next present evidence of the correlations between climate, ponds, and ducks. Controls on duck populations are quite complex and climate is not the only influence. The climate influence nonetheless works through the prevalence and character of ponds. For example, temporary and seasonal ponds are important to migrating waterfowl because they warm faster in the spring than the larger, deeper water bodies that can remain frozen, resulting in a higher recruitment of ducks (Johnson et al. 2008). Additionally, mink, a common predator, prefer permanent and semipermanent ponds also making temporary and seasonal wetlands 
PPR Precipitation Anomalies NW (left) and SE (right)

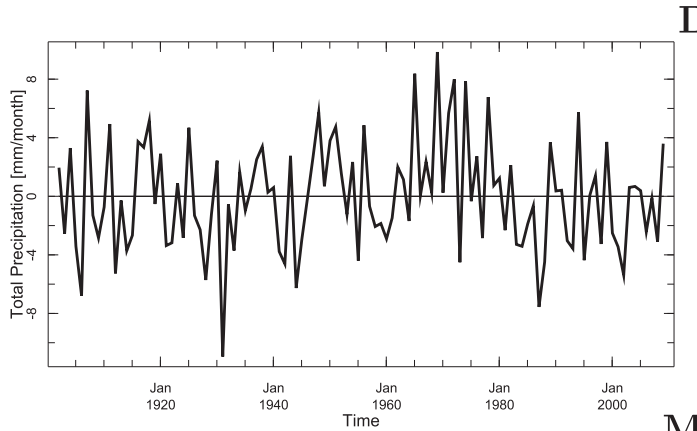

DJF

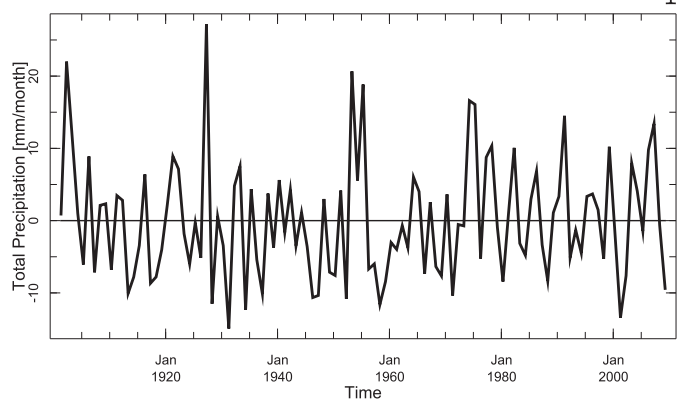

MAM
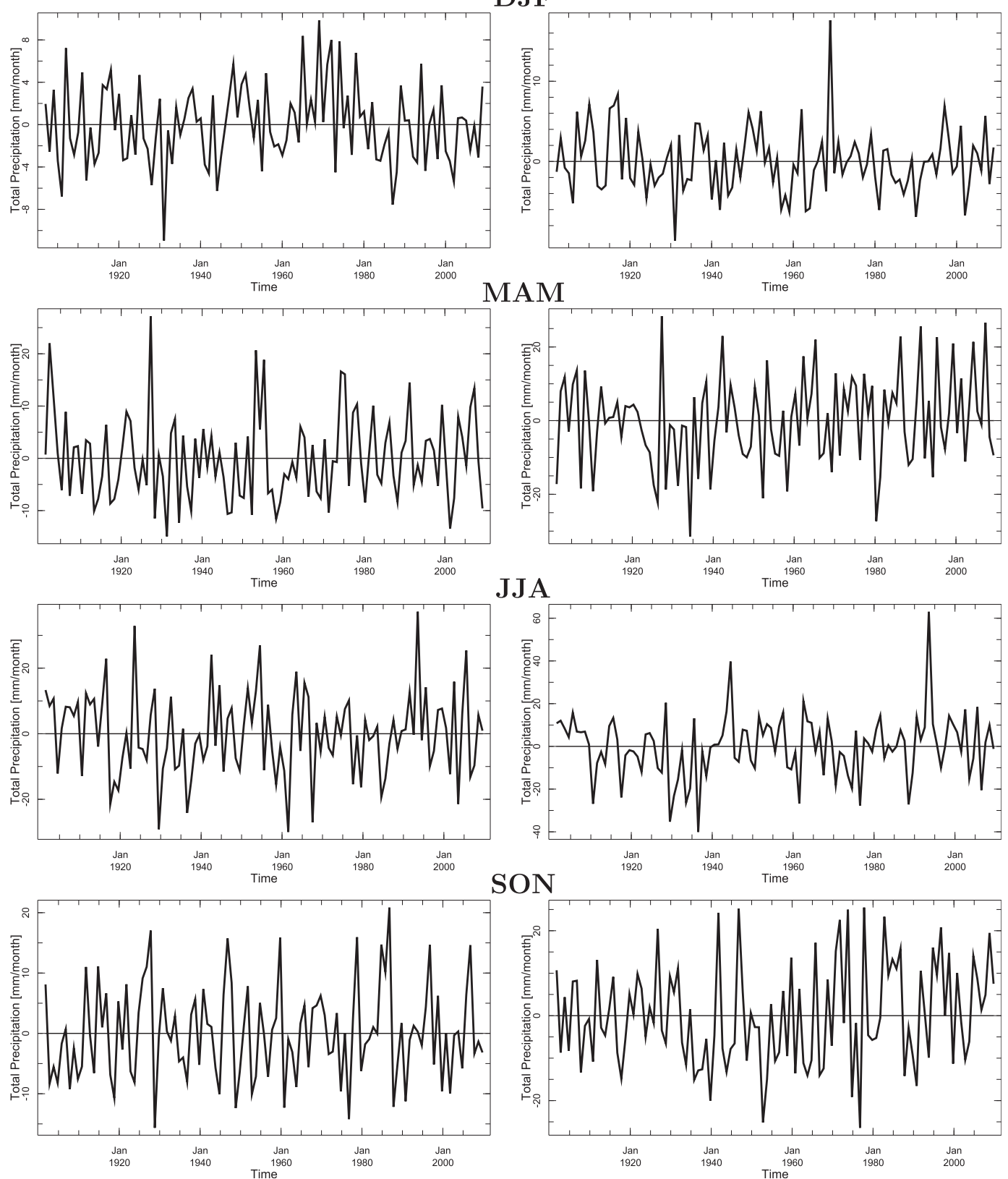

Figure 4. Precipitation anomaly time series for the (left) northwest and (right) southeast PPR by season based on GPCC data. Units are millimeters per month.

important habitats for duck recruitment (Arnold et al. 1990; Krapu et al. 2004). Grasslands surrounding potholes are important habitat for nesting for some species (but not the focus of this analysis). Once ducklings hatch, however, female ducks often move their ducklings to semipermanent wetlands for brood rearing, due in part 
Earth Interactions - Volume 18 (2014) • Paper No. 14 • Page 11

PPR Temperature Anomalies
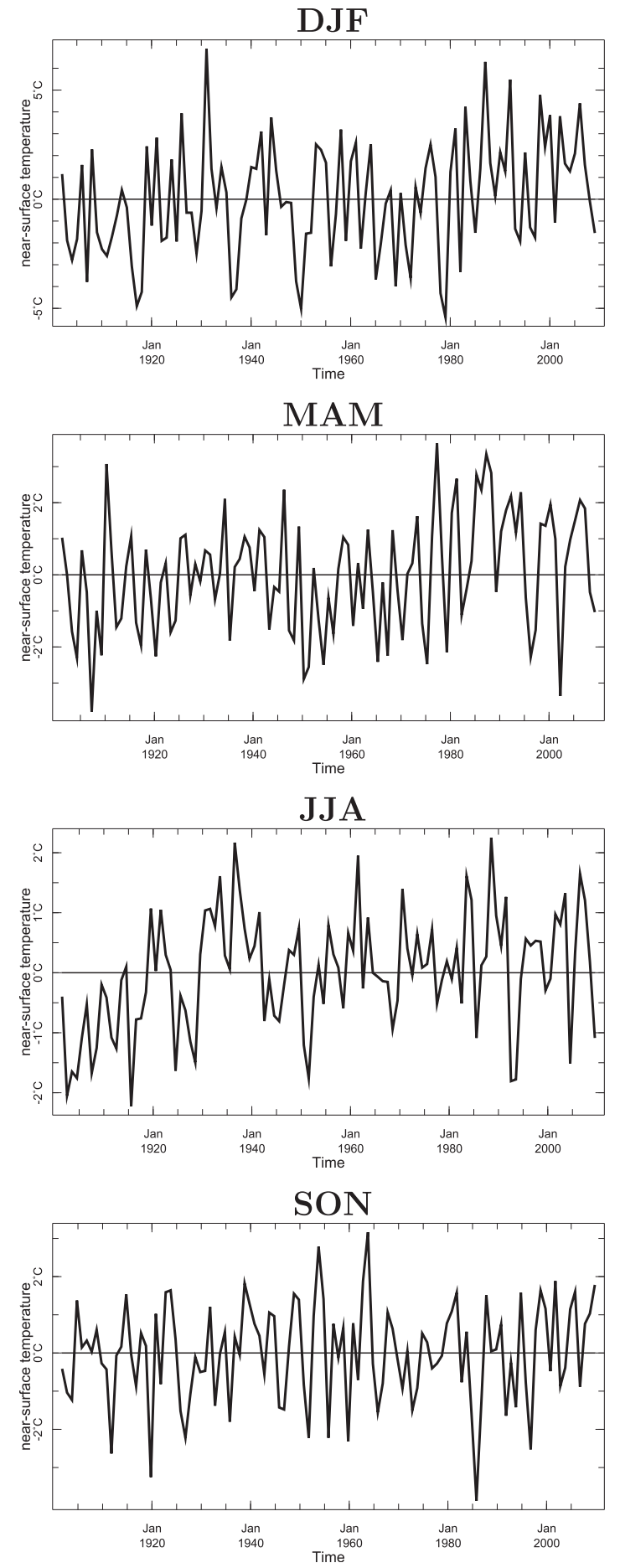

Figure 5. Surface air temperature anomaly time series for the entire PPR by season based on GPCC data. Units are degrees Celsius. 
Earth Interactions • Volume 18 (2014) • Paper No. 14 • Page 12

to the fact that the original water bodies may have become dry (Johnson et al. 1997, 2008). Preferences for certain habitat conditions also vary from species to species. For example, diving ducks, such as canvasbacks and redheads, prefer deeper wetlands for breeding habitat (Johnson et al. 1997). Adding to the complexity of modeling relationships between ponds and ducks, wetland selection is dependent on a multitude of other factors, including wetland-cover type, emergent vegetation characteristics, and interactions among other ducks (Raven et al. 2007). All of these factors are dynamic, with periods of drought and deluge having significant impacts on both the vegetation and chemistry of potholes (Labaugh et al. 1996). As demonstrated below and in previous studies, however, there is a clear association between duck populations, numbers of ponds, and climate.

\subsection{Decadal shifts in numbers of ponds and duck populations in the PPR}

Figure 6 shows time series of duck numbers (from 1955) and pond numbers (from 1974) for the PPR. With the exception of the mid-1970s in the southeast, there is a good agreement between duck and pond numbers, indicating the influence that environmental conditions have on waterfowl populations. This has been noted before (e.g., Niemuth and Solberg 2003; Johnson et al. 2005), but here results are shown for total ducks (i.e., all species) with data also extending to 2012. The multiyear drought in the late 1980s to around 1990 (which included the 1988 drought; Trenberth and Guillemot 1996; Seager and Hoerling 2014) was associated with a drop in duck and pond numbers across the PPR. After that, duck populations increased significantly in both the northwest PPR and southeast PPR, with the latter region seeing the greatest subsequent increase. This increase was clearly evident among mallards, as shown in Figure 7, although it was not uniform across all 12 species. The southeast PPR recruited a larger proportion of the total mallard population after 1990 than before (Figure 7). This postdrought shift in the 1990s matches quite well the distribution of ponds. For example, in the southeast PPR, Devil's Lake in North Dakota has seen considerable and sustained increases in inflow from the mid-1990s to the present (Vecchia 2008). Unlike the persistence of the positive shift in southeast relative to northwest PPR mallard numbers, however, pond numbers in the southeast PPR declined in the last decade, relative to those in the northwest PPR.

The reason that duck numbers increase with pond numbers and precipitation is the net result of several competing factors. With fewer ponds, ducks must travel longer distances and it can take up to 3 times longer for ducks to get from their nest to the nearby pond, requiring more energy and increasing exposure time to predators (Krapu et al. 2006). On the other hand, excessive precipitation might increase pond numbers but be harmful to newborn ducks because the hen will brood her ducklings during rainfall, protecting them from harm yet keeping them from foraging. Also, excessive precipitation can mean fewer invertebrates on the water surface and vegetation following rainfall, making feeding more difficult (Krapu et al. 2000, 2006).

The decadal shift in the 1990s is related to a shift in hydroclimate. To look at this we somewhat arbitrarily use 1995 as the divider and Figure 8 shows the difference 

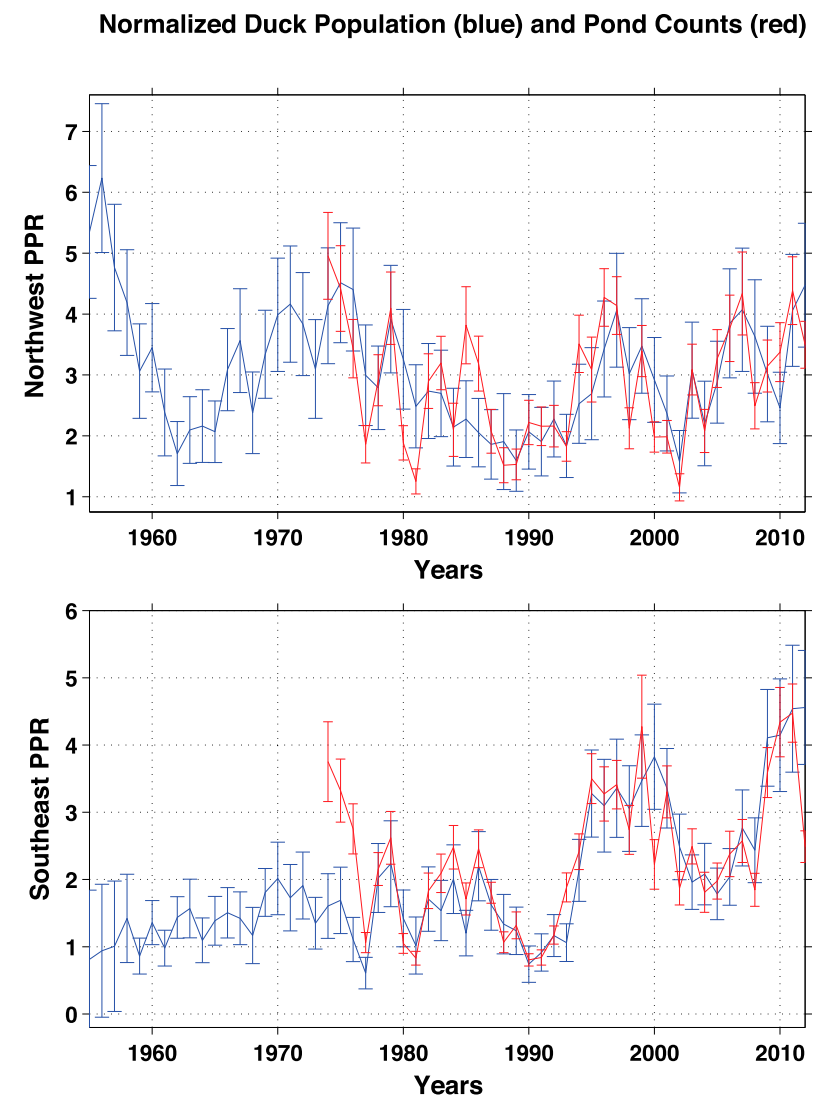

Figure 6. May pond counts with error bars (red) and total duck population with error bars (blue) for the (top) northwest PPR and (bottom) southeast PPR. The pond counts are available from 1974 to 2012, and the duck counts are available from 1955 to 2012. The pond and duck counts have been divided by their standard deviation for ease of plotting purposes. To convert to actual numbers multiply by, in millions, 4.3 for northwest ducks, 1.0 for northwest ponds, 3.3 for southeast ducks, and 6.0 for southeast ponds.

in precipitation for the post-1995 period relative to the pre-1995 period. This shows a shift to overall wetter conditions in the southeast PPR during the spring and fall. This is also evident in the time series in Figure 4. Although these wetter conditions did not lead to a sustained increase in the relative number of southeastern May ponds relative to those in the northwest, they may have led to other favorable changes in the ecosystem that led to the continuation of large numbers of mallards in the southeast PPR.

\subsection{Relationship of sea surface temperature variability to duck populations and pond numbers}

It is well established that North American hydroclimate is significantly affected by SST variability, especially in the tropical Pacific Ocean (e.g., Kiladis and Diaz 

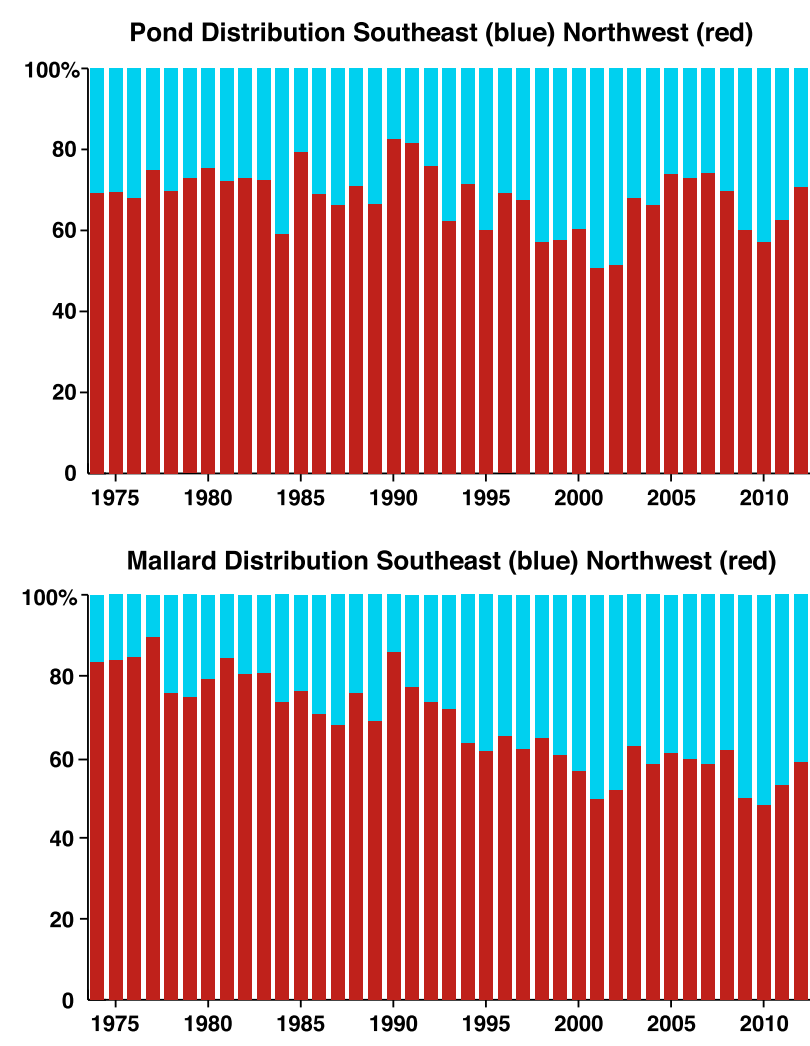

Figure 7. The numbers of (top) ponds and (bottom) mallards in the southeast and northwest PPR, expressed as a percentage of the total, from 1974 to 2012. The length of blue (red) bars shows the percentage of ponds or ducks in the southeast (northwest), with the two summing to $100 \%$. The shift of the relative mallard population to the southeast following the drought in the late 1980 s to around 1990 is clearly seen, despite the relative number of ponds in the southeast PPR returning to predrought numbers.

1989). For example, El Niño conditions, via atmospheric teleconnections, typically make southern parts of North America wetter than normal and the northwestern United States and southwestern Canada drier than normal. To determine any link to SST variability, the time series of duck populations and pond counts in May were correlated with time series of global SST in prior seasons. It was found that correlations between ducks, ponds, and SST variability were highest for SSTs in the previous winter. This is consistent with strong correlations between tropical Pacific SSTs and North American climate in that season (Kumar and Hoerling 1998) and with winter precipitation and temperature variations influencing spring moisture conditions in this region where most winter precipitation falls as snow and melts in spring. Maps of the correlation coefficient between May pond and duck numbers and December to February SST anomalies are shown in Figure 9 with positive (negative) coefficients indicating that high (low) duck population or pond numbers are associated with warmer (cooler) than normal SSTs at that location. There is a weak correlation with a La Niña-like or cold tropical Pacific phase of Pacific decadal variability in the previous winter season for pond counts across the PPR 


\section{Precipitation (1995-2010) - (1955-1994)}

a) DJF

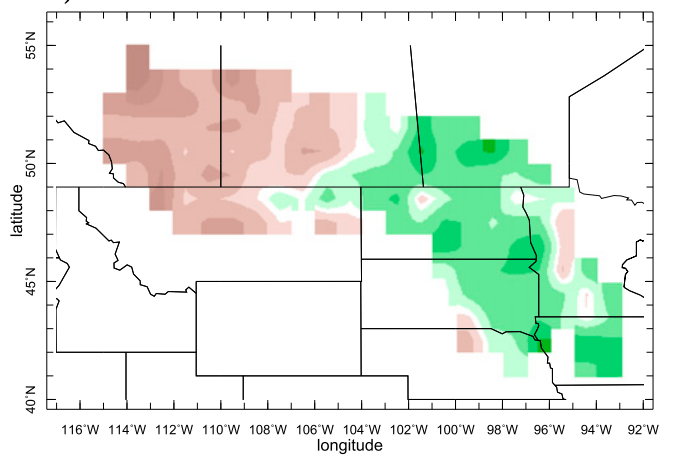

c) JJA

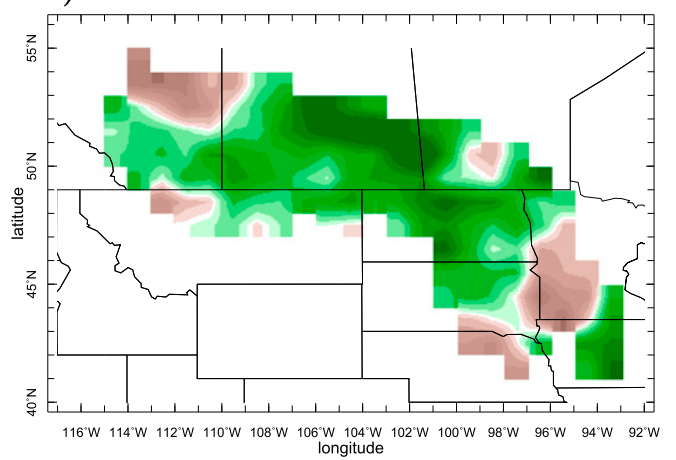

b) MAM

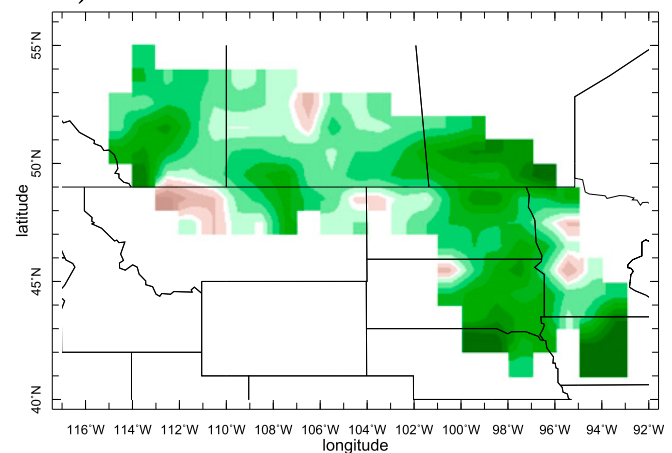

d) $\mathrm{SON}$

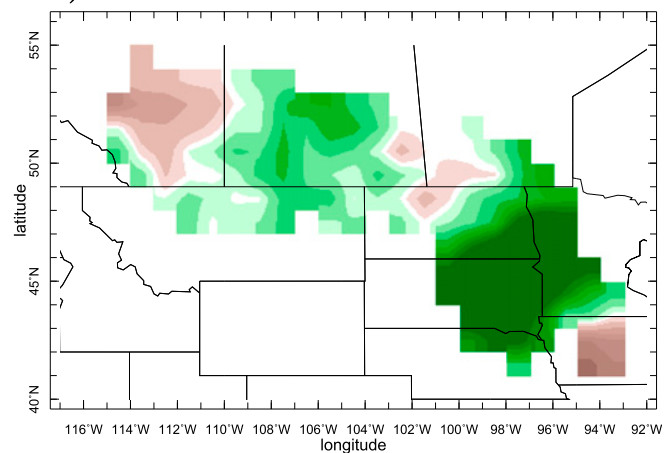

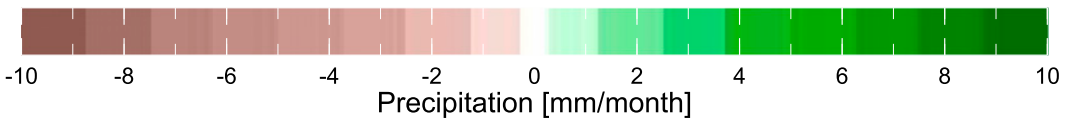

Figure 8. The precipitation difference between 1995-2010 and 1955-94. The temporal division is selected based on an earlier time when mallard populations were smaller in the southeast PPR and a later time when the populations increased in the southeast PPR after a drought.

and for duck populations in the northwest PPR (Figure 9). This association also seems to hold for duck numbers in the southeast PPR, but the shift to higher numbers in the 1990s was coincident with global ocean warming and hence large areas of positive correlation between duck numbers and SST obscure this signal. Figure 9 also shows maps of the correlation coefficient between time series of PDSI in the two PPR regions with time series of SST. It is seen that high values of PDSI (wet conditions) are very weakly correlated with cold tropical Pacific SSTs. To the extent these relations hold, it is because cooler than normal SSTs in the Pacific Ocean in winter force atmospheric circulation anomalies that generate cooler temperatures throughout the PPR and increased precipitation in the northwest PPR (not shown). Cooling and wetting would be expected to increase pond numbers and, potentially, duck numbers. All these correlations are weak, however, which is 


\section{DJF Observed SSTA Correlation}

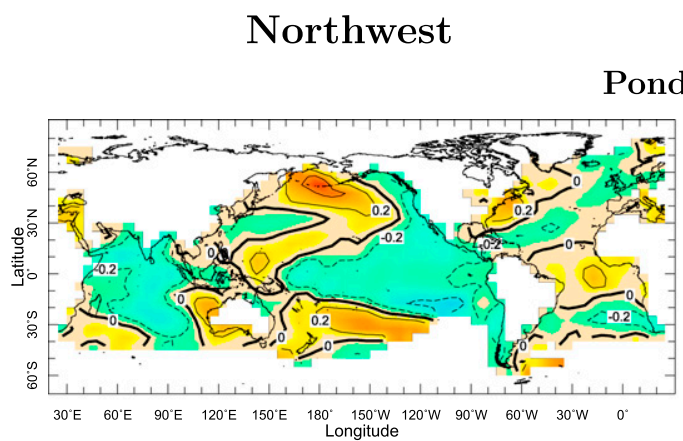

Southeast

Pond Counts

Duck Population
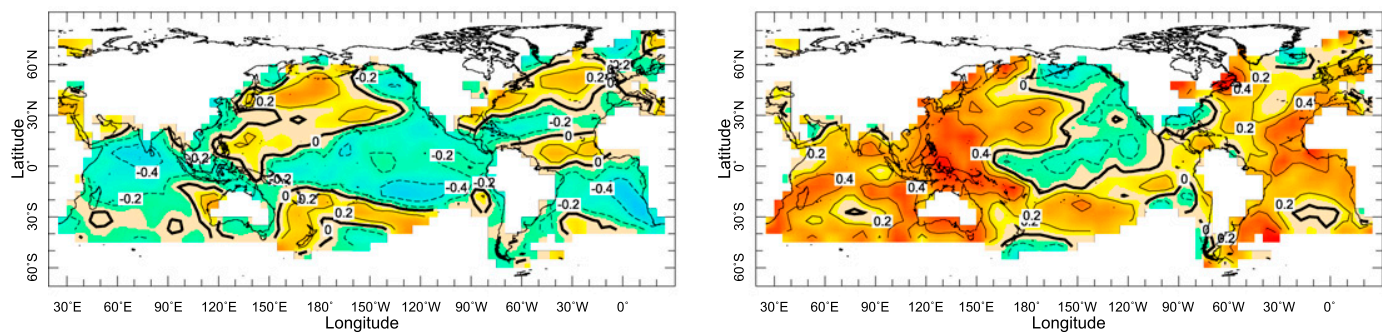

PDSI
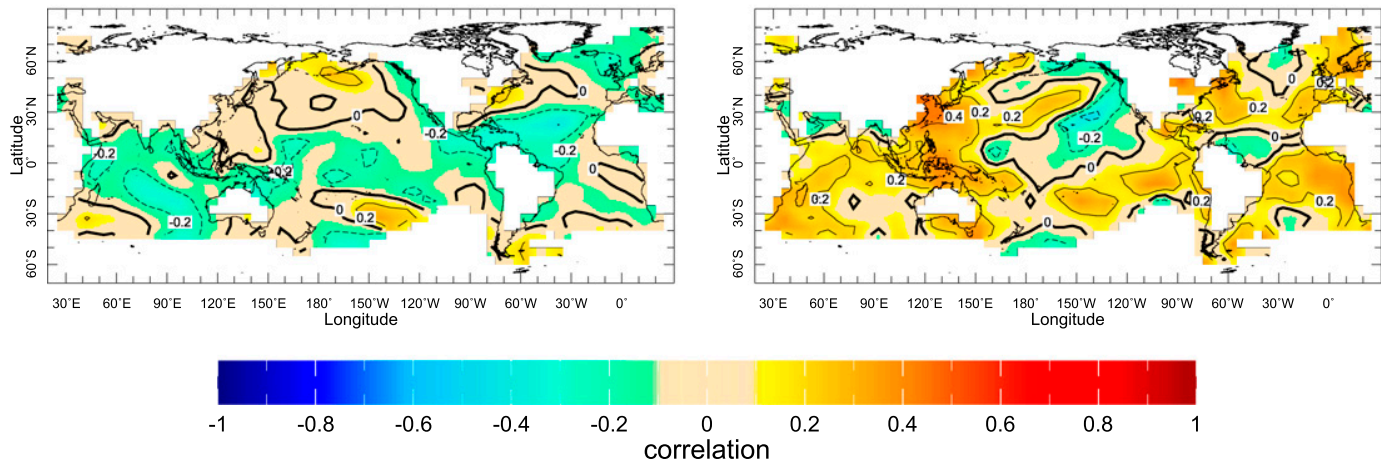

Figure 9. The correlation between (łop) pond numbers, (middle) duck population, and (bottom) PDSI in May and SST of the previous December through February winter for the (left) northwest PPR and (right) southeast PPR. Pond and duck numbers are weakly related to La Niña-like condition in the Pacific Ocean. The duck-SST relationship for the southeast PPR is influenced by the upward trend in the former, which obscures any La Niña-like connection.

likely associated with the fact that the PPR region lies close to a nodal line between opposite-sign tropical Pacific-driven precipitation anomalies to its north and south (e.g., Kiladis and Diaz 1989; Seager et al. 2005). Correlations between duck and pond numbers and tropospheric geopotential height fields (not shown) also show 


\section{PDSI (green)}
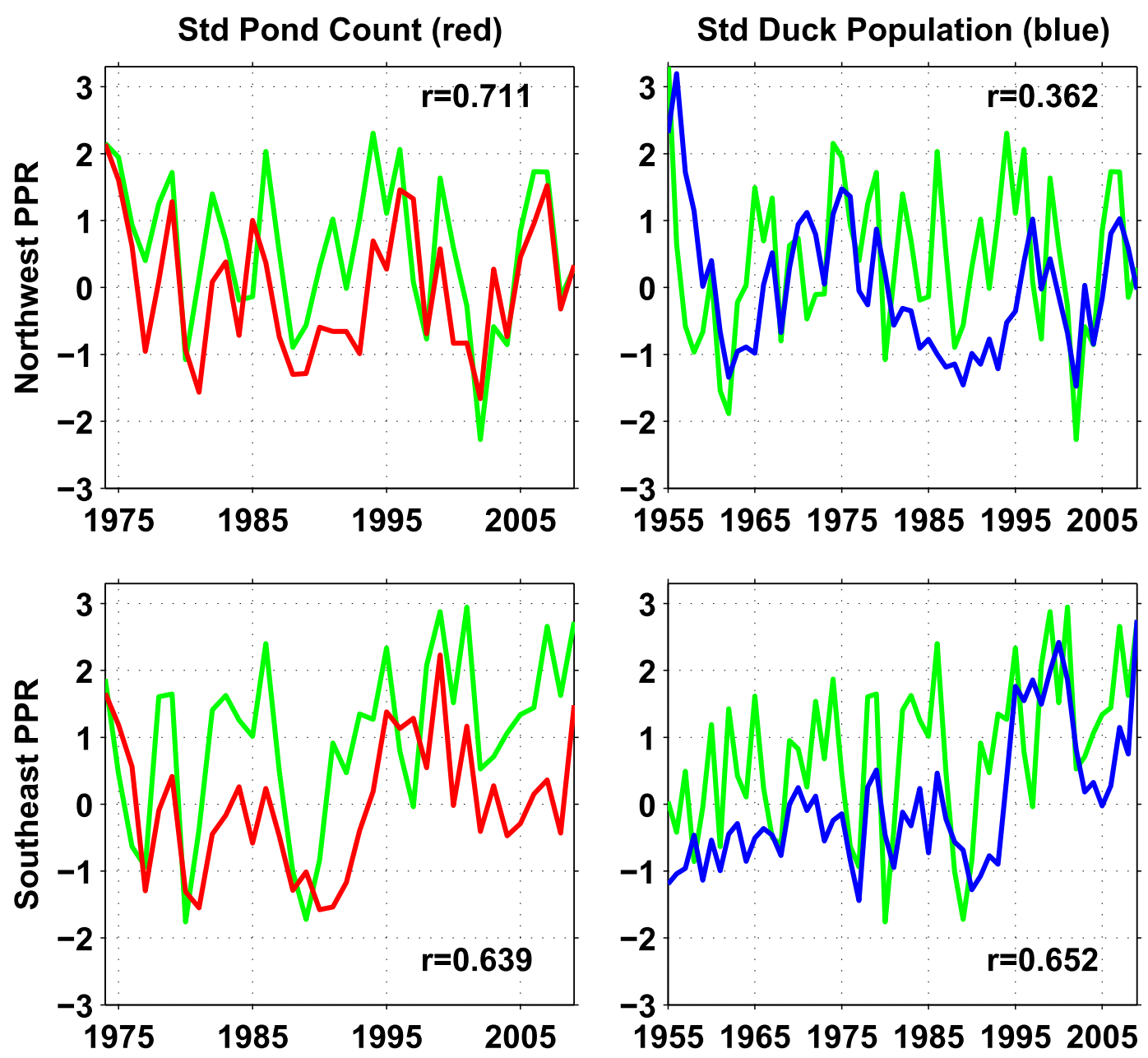

Figure 10. Time series of (left) pond numbers (1975-2012) and (right) duck numbers (1955-2012), both standardized, with the May PDSI for the (top) northwest and (bottom) southeast PPR. The correlation coefficients between the time series are noted as inset values.

the weak connection to the tropical Pacific Ocean and do not show a role for other patterns of circulation variability (e.g., the Arctic Oscillation).

\subsection{Relationships between Palmer drought severity index, pond numbers, and duck populations}

Despite the limited influence of the oceans, May pond numbers and duck populations are closely linked to the May PDSI (Figure 10). The PDSI is an index of moisture availability in the soil and is influenced by both temperature (via 
Earth Interactions - Volume 18 (2014) • Paper No. 14 • Page 18

evapotranspiration) and precipitation. May PDSI will reflect the accumulated influence of precipitation and temperature over the previous winter and into the spring and is therefore logically related to the number of ponds. May PDSI and duck populations have weaker correlations, but there is still a clear relationship. The large increase in southeast PPR duck populations is correlated with sustained wetter conditions following the drought in the late 1980s to around 1990. Other seasonal combinations of PDSI were analyzed (e.g., winter PDSI), but the May PDSI had by far the strongest connection to duck and pond numbers.

Further investigation showed that both temperature and precipitation individually correlated with the number of May ponds but not as strongly as their combined effect in PDSI. In general, increased temperature had a negative impact on pond counts and increased precipitation in every season except summer was linked to increased May pond numbers. All correlations were weaker for duck numbers, as expected because of the numerous other factors impacting duck success. Furthermore, it is likely that there is a lag effect of climate on population because a year with poor conditions for duck nesting and rearing would not be reflected in the population counts until the following year. Associating duck numbers with climate in previous years or examining the year-to-year change in duck numbers did not, however, lead to consistently improved correlations with climate variables.

\section{Explaining past PPR hydroclimate trends: Natural variability or climate change?}

The prior literature on climate and the PPR has often mentioned the strengthening over recent decades of the climatological precipitation gradient between the wetter eastern part and the drier western part of the region (e.g., Johnson et al. 2005). However, these studies did not address whether the strengthening gradient arose from natural variability and hence could reverse or was a response to rising greenhouse gases and, consequently, might be expected to continue. We therefore analyzed trends in precipitation over the longest period possible from 1901 to 2005 for the two regions and for each season. Trends over the same period were also calculated for one ensemble member of the historical simulations of 41 climate models participating in CMIP5 (Figure 11). The northwest PPR has seen little change in observed (from GPCC) precipitation while the southeast PPR has seen increases in observed precipitation in spring, summer, and fall by as much as $10 \%$ per century; winter precipitation in the southeast PPR has decreased by the same magnitude. These regional changes have yielded a strengthening of the climatological precipitation gradient and are one reason why previous studies (Millett et al. 2009) have suggested the most productive regions of the PPR may shift toward the southeast PPR.

Despite the observed changes in the two PPR regions, the CMIP5 model simulations indicate the wetting trend in the southeast PPR does not appear to be primarily a result of climate change. The best estimate of the radiatively forced changes in precipitation to date is the multimodel mean of the historical simulations of the CMIP5 models (see section 2 for an explanation of why this is so). In Figure 11 we show the multimodel mean, representing the models' response to changes in radiative forcing, as well as the projections from the individual model 

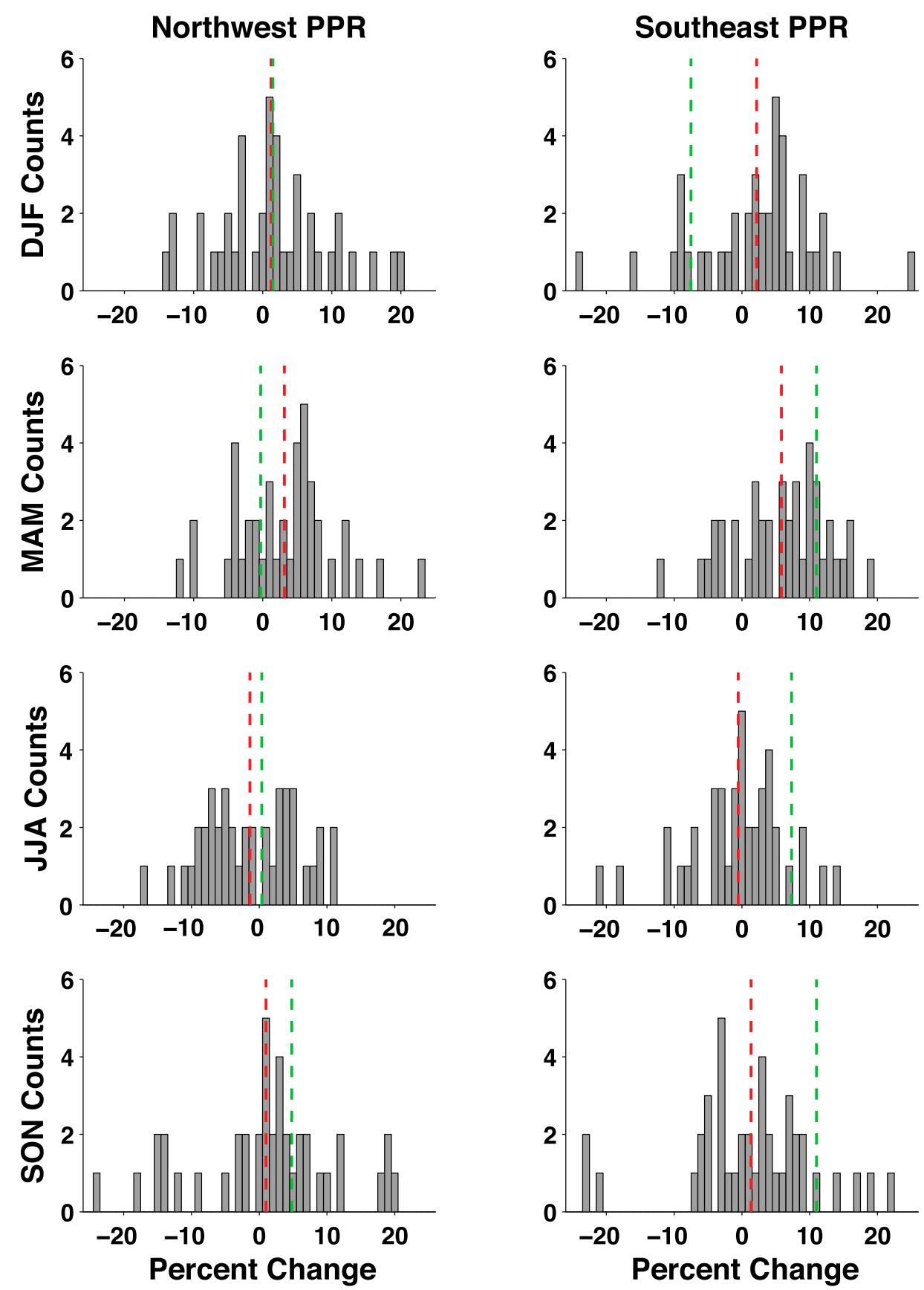

Figure 11. Histograms of the 1901-2005 trends in precipitation from historical simulations of 41 global climate models from the CMIP5 experiment forced with past variation in trace gases, solar irradiance, volcanism, etc. The multimodel mean is shown as the red vertical bar and the observed value is shown as the green vertical bar. The vertical axis is the number of models with that simulated percent change in precipitation. Results are shown by season and for the (left) northwest and (right) southeast PPR. 
Earth Interactions - Volume 18 (2014) • Paper No. 14 • Page 20

runs, which include both the forced response and modeled internal variability. The trends of the individual runs are spread in a quite balanced way between wetting and drying and in both regions and in all seasons the observed trend is within the model spread. Furthermore, the mean of the model trends is close to zero. This leads to two conclusions: First, the observed precipitation trends are within the range of what models suggest could be generated by internal climate variability alone. Second, the near-zero multimodel means suggest that changes in radiative forcing to date have caused relatively little change in precipitation. The one exception to this second conclusion is the southeast PPR in spring. Here, because the multimodel mean trend is positive and the trends in the individual runs are mostly positive, the model simulations suggest that increased radiative forcing has caused an increase in precipitation. Even so, this forced response, as represented by the multimodel mean, is only about half the strength of the observed wetting trend in spring in the southeast PPR. This is consistent with the observed wetting trend in the southeast PPR in spring being a mix of a forced response that is augmented by natural variability. In contrast, during summer and fall, because the multimodel means are close to zero and the spreads of the trends of the individual simulations are not preferentially wet, the models suggest that the observed wetting trends are most likely due to natural climate variability alone. Trends that have arisen from natural variability, as opposed to a response to increasing greenhouse gas radiative forcing, could conceivably reverse in the future.

\section{Model projections of future hydroclimate of the PPR}

While the past climate variations in the PPR region have likely been dominated by natural variability, the problem of human-induced climate change is a real one, and it is important to determine what this implies for the future of the PPR. Prior work has shown that the CMIP5 models project wetter conditions for coming decades in the northern United States in the cold season but drier conditions across most of central and northern North America in summer (Seager et al. 2013). Here we revisit these projections focusing in on the PPR.

Maps of the precipitation trends projected for the 55-yr period from 2006 to 2060, using the 37-model ensemble mean, are shown in Figure 12. This mean primarily represents the change expected from increased greenhouse gases in the atmosphere and projects precipitation increases in the winter, spring, and fall with the largest increase in the spring. Summer precipitation is expected to stay roughly the same in the northwest PPR and slightly decrease in the southeast PPR. These magnitudes of change are comparable to the observed trends from 1901 to 2005. There do not appear to be large differences between the projected changes in the northwest and southeast PPR.

The PPR is also projected to become much warmer, with a $3^{\circ}-4^{\circ} \mathrm{C}$ warming trend from 2006 to 2060 (Figure 13). Warming is highest in the winter on the northeastern fringes of the PPR due to the equatorward expression of the polar amplification warming signal. These increases in temperature will lead to higher rates of evapotranspiration. To assess the impact of both rising temperatures and precipitation changes, we examine the changes in precipitation minus evapotranspiration $(P-E)$ with positive (negative) values implying increased (decreased) net fluxes of water from the atmosphere to the surface. Projections of 
Earth Interactions - Volume 18 (2014) • Paper No. 14 • Page 21
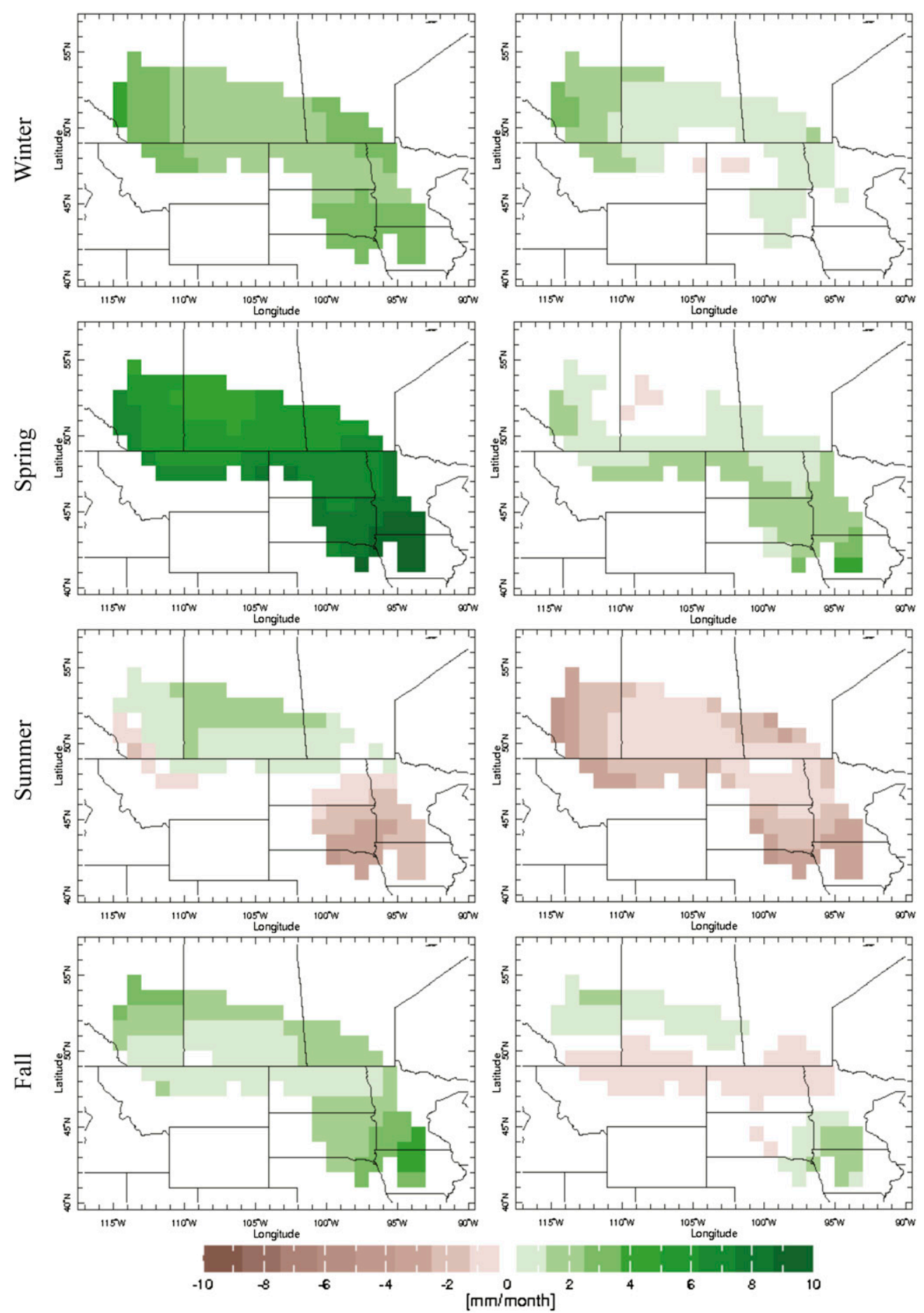

Figure 12. Projected trends in (left) precipitation and (right) $P-E$ over the $55-y r$ period from 2006 to 2060 from the multimodel mean of 37 climate models subject to the RCP8.5 emissions scenario by season. Values are in millimeters per month. 

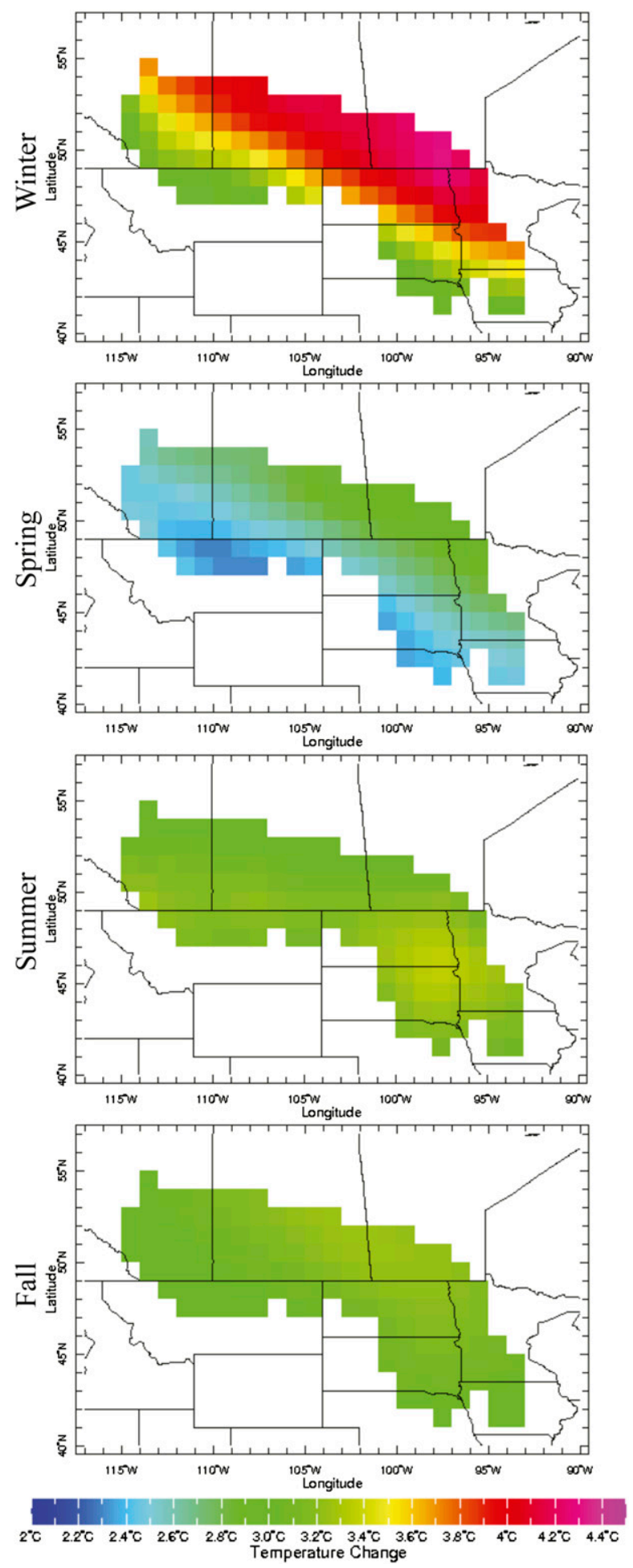

Figure 13. As in Figure 12, but for projected change in surface air temperature in degrees Celsius. 
Earth Interactions - Volume 18 (2014) • Paper No. 14 • Page 23

$P-E$ for the same 2006-60 period show that much of the increases in precipitation are, from the perspective of surface moisture balance, offset by the increases in $E$ driven by increases in temperature (Figure 12). There is still a net wetting trend in the winter and spring, albeit smaller, but the summer shows a distinct drying trend throughout the PPR. The fall shows relatively little change in $P-E$. The projected changes in $P-E$ are quite spatially uniform but do suggest that increasing moisture will prevail in the southeast PPR in spring while the summer drying will impact all parts of the PPR.

Finally, to provide an assessment of how the forced change in precipitation compares to past changes and to modeled internal variability, Figure 14 presents histograms, analogous to Figure 11, of the projected changes in precipitation from runs of the 37 models. In both the northwest and southeast PPR in winter and spring, there is considerable model agreement (in the sense that a clear majority of models have wet trends and the multimodel mean trend is also to wetter conditions) that precipitation will increase. In contrast, the models suggest little change in summer and fall. These seasonal changes in $P$ are why the effects of warming generate widespread negative changes in $P-E$ only in summer and fall.

The question also arises of whether, despite the mean changes over the coming decades, hydroclimate conditions in the extreme years do not change. We also analyzed this by computing for every model the $P-E$ averaged across the wettest $5 \%, 10 \%$, and $25 \%$ of seasons for the 1901-2005 period and then again for the 2006-60 period. The largest change in mean $P-E$ is the drying in the summer season in both the northwest and southeast PPR. In both regions this mean reduction was accompanied by a reduction in $P-E$ in the wettest years (not shown). Therefore, mean drying in summer is accompanied by a drying of the wettest summers as well.

\section{Conclusions and discussion}

The Prairie Pothole Region is the most productive waterfowl habitat in the world and critical for North America's duck populations, making climate change in the region of great interest and importance. Millions of ducks migrate to the region in spring to breed and raise their young in subsequent months. The breeding success of the waterfowl depends on millions of permanent, semipermanent, and temporary ponds located within glacial potholes. The number of these ponds-and hence the duck populations that they support-is dependent on variations in precipitation and temperature (which influences evaporation from the ponds and evapotranspiration from inflow watersheds). Here we have examined past climate variations and their links to pond and duck numbers and also looked at future climate projections for the region. Our conclusions are as follows:

- The numbers of ponds and duck populations in May in the PPR agree quite well over recent decades. That the pond numbers respond to climate variations corroborates the importance of climate variability and change for future duck populations in the region. The multiyear drought in the late 1980s to around 1990 was associated with a shift of duck populations to the wetter southeast PPR. Indeed, even after pond numbers recovered in the northwest PPR after the drought, mallard numbers remained at increased 

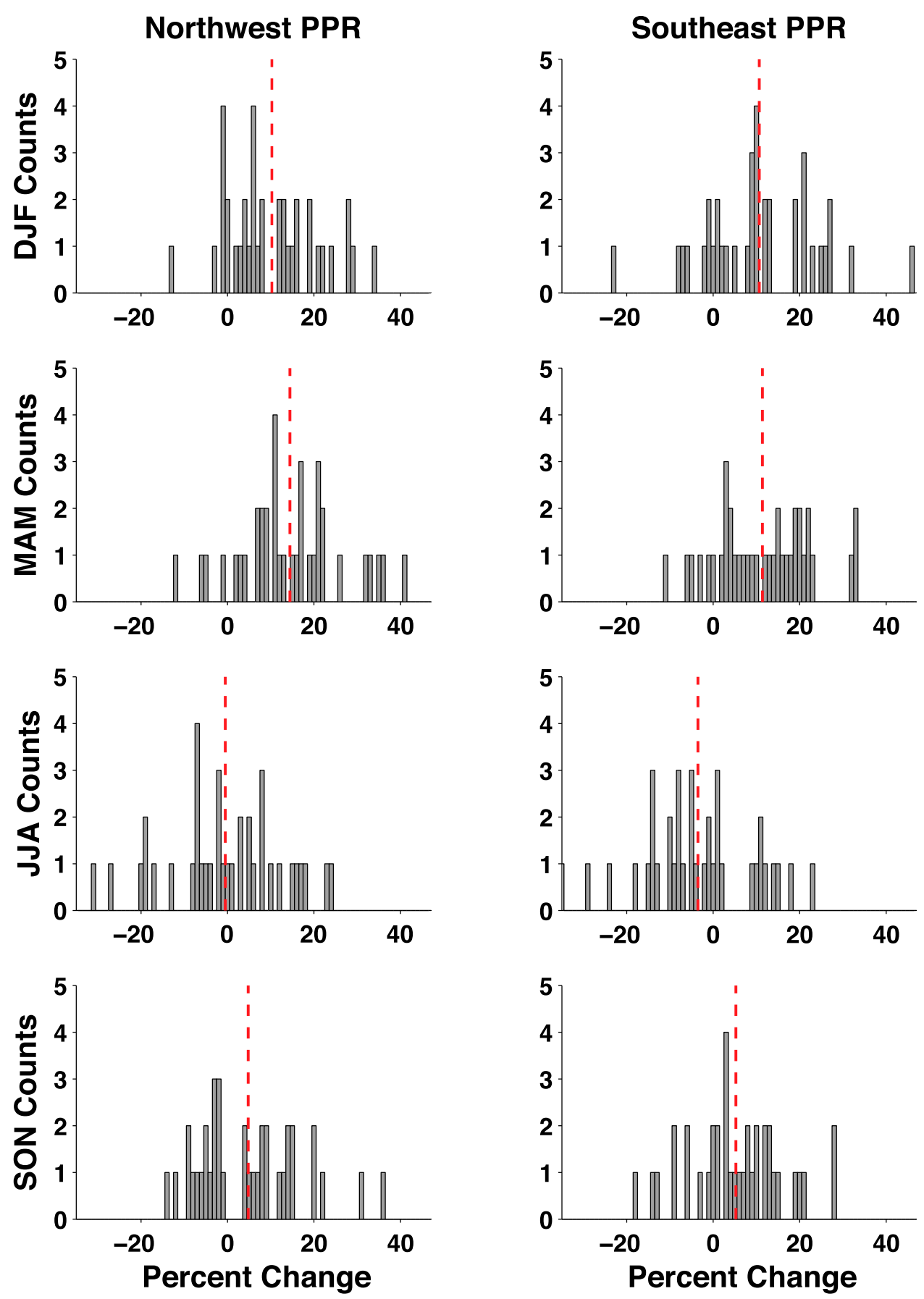

Figure 14. Histograms of the 2006-60 trends in precipitation from projections of 37 global climate models from the CMIP5 experiment forced with the RCP8.5 emissions scenario by season and for the (left) northwest and (right) southeast PPR. The vertical axis is the number of models with that percent change in precipitation. The multimodel mean is shown as the red vertical bar. 
Earth Interactions - Volume 18 (2014) • Paper No. 14 • Page 25

levels in the southeast, which now holds about $40 \%$ of the total mallard population as opposed to under $20 \%$ before the drought.

- The pond and duck numbers in May are weakly related to cold conditions in the tropical Pacific Ocean in the preceding winters. This occurs as part of the teleconnection between the El Niño-Southern Oscillation with La Niña conditions leading to drier conditions in southern North America and wetter conditions in northern North America. The PPR is in the wetter than normal region during La Niña events but close to the nodal line, and hence the correlations are weak. Consequently, there will be little skill in prediction of seasonal pond and duck numbers in the PPR based on seasonal prediction of prior SSTs and their impacts on precipitation and temperature across the PPR.

- The May pond and duck numbers are closely related to the May Palmer drought severity index, a measure of surface moisture availability, as previously noted for a shorter period by Sorenson et al. (1998). This indicates a climate control on the "duck factory," even if only a modest fraction of the important climate variability is controlled by ocean variations. More research, informed by biological and ecological considerations, is needed to assess whether duck populations can be more closely correlated with climate variability.

- Over past decades, precipitation amounts in the northwest PPR have been relatively stable but the southeast PPR has become wetter in all seasons other than winter. This wet trend is not strongly influenced by radiatively forced climate change. According to the CMIP5 models, radiatively forced change may have contributed perhaps half of the wet trend in spring, but the contribution in other seasons is negligible. The observed trends are within the range of what the models indicate can occur from natural climate variability. Therefore, we conclude that past changes, including wetting trends in the southeast PPR, have been dominated by natural climate variability. Extrapolating observed trends into the future is thus not warranted.

- The CMIP5 models project that precipitation will increase in coming decades across the PPR in all seasons but summer. Maximum increases by 2060 are about $10 \%$ in winter and spring but the models also project that, due to rising temperatures, the change in precipitation minus evapotranspiration, $P-E$, is much less and even negative in the summer. These changes are quite uniform across the PPR.

Our findings that temperature and precipitation variability have a large impact on PPR wetland and waterfowl dynamics confirm previous studies. In dry years, the number of ponds decreases. For example, during the multiyear drought in the late 1980s to around 1990 the number of ponds and ducks dropped in lockstep. Presumably this is because under drier conditions basins that would normally act as semipermanent bodies may behave as seasonal wetlands, and many seasonal wetlands may act as temporary wetlands, drying within 3 weeks (Johnson et al. 2010). This has an overall negative impact on the duck populations, given their positive correlation with the number of PPR wetlands (Batt et al. 1989; Krapu et al. 2000; Niemuth and Solberg 2003). The opposite occurs during deluge years, with 
not only increased wetlands but also more wetlands that last into midsummer. This is usually accompanied by a surge in duck populations (Johnson et al. 2008).

Despite this close correspondence between ducks, ponds, and climate, it should not be assumed that past changes will continue into the future. Analysis of climate models suggests that the past changes have occurred primarily because of natural climate variability, with the effects of human-induced climate change limited to a modest wetting of the southeast PPR in spring. On the other hand, as humaninduced climate change gains strength, the PPR will see both increased precipitation (except in summer) and increased temperature. Net moisture fluxes at the surface will be positive in winter but negative in summer and quite uniform across the PPR. The climatological gradient from wet to dry going from east to west is therefore not expected to intensify or weaken as a result of climate change.

The implications for the potholes and waterfowl are not immediately clear. Overall wetting in the drier western region might make ponds more biologically productive and do the opposite in the wetter east by lengthening cover times. Overall drying would probably favor the eastern potholes (Johnson et al. 2005, 2010). The projected changes are, however, seasonally variable, making simple inferences difficult to establish. This reality points to the need to use the climate projections presented here as drivers for hydrological-ecological models of the potholes landscape as in Johnson et al. (2005, 2010), something that is eminently doable in the near term. The current work indicates that the climate change assumptions made in prior work were not good approximations of the changes that state-of-the-art climate models project, highlighting both the need and achievability of improved projections of hydrological and ecological change in this important region.

Acknowledgments. This work was supported by NSF Award AGS-1243204 ("Linking near-term future changes in weather and hydroclimate in western North America to adaptation for ecosystem and water management") and NOAA Award NA08OAR4320912 ("Global decadal hydroclimate variability and change"). We particularly thank Susan Skagen (U.S. Geological Survey), Michael Olson and Richard Nelson (U.S. Fish and Wildlife Service), and Helen Sofaer (Colorado State University) for their careful readings, which led to a more informative and practically useful paper. TB acknowledges the Lamont summer undergraduate intern program for additional support. We thank Haibo Liu for assembling the CMIP5 model database at Lamont. We thank two anonymous reviewers for detailed and thoughtful comments and criticisms. The authors declare no conflicts of interest.

\section{References}

Arnold, T. W., E. K. Fritzell, and F. R. Tzell, 1990: Habitat use by male mink in relation to wetland characteristics and avian prey abundance. Can. J. Zool., 68, 2205-2208, doi:10.1139/z90-306.

Badiou, P., R. McDougal, D. Pennock, and B. Clark, 2011: Greenhouse gas emissions and carbon sequestration potential in restored wetlands of the Canadian Prairie Pothole Region. Wetlands Ecol. Manage., 19, 237-256, doi:10.1007/s11273-011-9214-6.

Batt, B. D. J., M. G. Anderson, C. D. Anderson, and F. D. Caswell, 1989: The use of prairie potholes by North American ducks. Northern Prairie Wetlands, A. van der Valke, Ed., Iowa State University Press, 204-227. 
Carver, E., 2006: Economic impact of waterfowl hunting in the United States. U.S. Department of the Interior Fish and Wildlife Service Tech. Rep., 13 pp.

Dahl, T. E., 1990: Wetland losses in the United States 1780s to 1980s. U.S. Department of the Interior Fish and Wildlife Service Tech. Rep., 13 pp.

Gleason, R. A., N. H. Euliss, B. A. Tangen, and M. K. Laubhan, 2011: USDA conservation program and practice effects on wetland ecosystem services in the Prairie Pothole Region. Ecol. Appl., 21, S65-S81, doi:10.1890/09-0216.1.

Harris, I., P. D. Jones, T. J. Osborn, and D. H. Lister, 2014: Updated high-resolution grids of monthly climatic observations-The CRU TS3.10. Int. J. Climatol., 34, 623-642, doi:10.1002/joc.3711.

Johnson, R. R., K. F. Higgins, M. L. Kjellsen, and C. R. Elliot, 1997: Eastern South Dakota wetlands. South Dakota State University Tech. Rep., 28 pp.

— , F. T. Oslund, and D. R. Hertel, 2008: The past, present and future of prairie potholes in the United States. J. Soil Water Conserv., 63, 84A-87A, doi:10.2489/jswc.63.3.84A.

Johnson, W. C., B. Millett, T. Gilmanov, A. Richard, G. R. Guntenspergen, and D. E. Naugle, 2005: Vulnerability of northern prairie wetlands to climate change. Bioscience, 55, 863-872, doi:10.1641/0006-3568(2005)055[0863:VONPWT]2.0.CO;2.

— climate. Bioscience, 60, 128-140, doi:10.1525/bio.2010.60.2.7.

Johnston, C., 2013: Wetland losses due to row crop expansion in the Dakota Prairie Pothole Region. Wetlands, 33, 175-182, doi:10.1007/s13157-012-0365-x.

Kaplan, A., M. A. Cane, Y. Kushnir, A. C. Clement, M. B. Blumenthal, and B. Rajagopalan, 1998: Analyses of global sea surface temperature: 1856-1991. J. Geophys. Res., 103, 1856718589, doi:10.1029/97JC01736.

Kiladis, G. N., and H. F. Diaz, 1989: Global climatic anomalies associated with extremes in the Southern Oscillation. J. Climate, 2, 1069-1090, doi:10.1175/1520-0442(1989)002<1069: GCAAWE $>2.0 . \mathrm{CO} ; 2$.

Krapu, G. L., P. J. Pietz, D. A. Brandt, and R. R. Cox, 2000: Factors limiting mallard brood survival in prairie pothole landscapes. J. Wildl. Manage., 64, 553-561, doi:10.2307/3803253.

,,--- , and 2004: Does presence of permanent fresh water affect recruitment in prairienesting dabbling ducks? J. Wildl. Manage., 68, 332-341, doi:10.2193/0022-541X(2004)068[0332: DPOPFW]2.0.CO;2.

,,$-- \ldots$, and -2006 : Mallard brood movements, wetland use, and duckling survival during and following a prairie drought. J. Wildl. Manage., 70, 1436-1444, doi:10.2193/ 0022-541X(2006)70[1436:MBMWUA]2.0.CO;2.

Kumar, A., and M. P. Hoerling, 1998: Annual cycle of Pacific-North American seasonal predictability associated with different phases of ENSO. J. Climate, 11, 3295-3308, doi:10.1175/ 1520-0442(1998)011<3295:ACOPNA>2.0.CO;2.

Labaugh, J. W., T. C. Winter, G. A. Swanson, D. O. Rosenberry, R. D. Nelson, and N. H. Euliss, 1996: Changes in atmospheric circulation patterns affect mid-continent wetlands sensitive to climate. Limnol. Oceanogr., 41, 864-870, doi:10.4319/1o.1996.41.5.0864.

Larson, D., 1995: Effects of climate on numbers of northern prairie wetlands. Climatic Change, 30, 169-180, doi:10.1007/BF01091840.

Millett, B., W. C. Johnson, and G. Guntenspergen, 2009: Climate trends of the North America Prairie Pothole Region 1906-2000. Climatic Change, 93, 243-267, doi:10.1007/s10584-008-9543-5.

Niemuth, N., and J. Solberg, 2003: Response of waterbirds to number of wetlands in the Prairie Pothole Region of North Dakota, U.S.A. Waterbirds, 26, 233-238, doi:10.1675/1524-4695(2003)026[0233: ROWTNO]2.0.CO;2.

Preston, T. M., T. L. Chesley-Preston, and J. M. Thamke, 2014: A GIS-based vulnerability assessment of brine contamination to aquatic resources from oil and gas development in eastern Sheridan County, Montana. Sci. Total Environ., 472, 1152-1162, doi:10.1016/ j.scitotenv.2013.09.027. 
Earth Interactions • Volume 18 (2014) • Paper No. 14 • Page 28

Raven, G. H., L. M. Armstrong, D. W. Howerter, and T. W. Arnold, 2007: Wetland selection by mallard broods in Canada's prairie-parklands. J. Wildl. Manage., 71, 2527-2531, doi:10.2193/2004-022.

Schneider, U., A. Becker, P. Finger, A. Meyer-Christoffer, B. Rudolf, and M. Ziese, 2011: GPCC full data reanalysis version 6.0 at $0.5^{\circ}$ : Monthly land surface precipitation from rain gauges built on GTS-based and historic data. Global Precipitation Climatology Centre, doi:10.5676/ DWD_GPCC/FD_M_V6_050.

Seager, R., and M. P. Hoerling, 2014: Atmosphere and ocean origins of North American drought. J. Climate, 27, 4581-4606, doi:10.1175/JCLI-D-13-00329.1.

—, N. Harnik, W. A. Robinson, Y. Kushnir, M. Ting, H. P. Huang, and J. Velez, 2005: Mechanisms of ENSO-forcing of hemispherically symmetric precipitation variability. Quart. J. Roy. Meteor. Soc., 131, 1501-1527, doi:10.1256/qj.04.96.

— M. Ming, C. Li, N. Naik, B. Cook, J. Nakamura, and H. Liu, 2013: Projections of declining surface water availability for the southwestern U.S. Nat. Climate Change, 3, 482-486, doi:10.1038/nclimate 1787 .

—_ and Coauthors, 2014: Dynamical and thermodynamical causes of large-scale changes in the hydrological cycle over North America in response to global warming. J. Climate, doi:10.1175/JCLI-D-14-00153.1, in press.

Shaw, S. P., and G. Fredine, 1956: Wetlands of the United States-Their extent and their value to waterfowl and other wildlife. U.S. Department of the Interior Circular 39, 67 pp.

Smith, G. W., 1995: A critical review of the aerial and ground surveys of breeding waterfowl in North America. U.S. Department of the Interior National Biological Science Rep. 5, 261 pp.

Sorenson, L., R. Goldberg, T. Root, and M. Anderson, 1998: Potential effects of global warming on waterfowl populations breeding in the northern Great Plains. Climatic Change, 40, 343-369, doi:10.1023/A:1005441608819.

Trenberth, K., and C. J. Guillemot, 1996: Physical processes involved in the 1988 drought and 1993 floods in North America. J. Climate, 9, 1288-1298, doi:10.1175/1520-0442(1996)009<1288: PPIITD>2.0.CO;2.

USFWS/CWS, 1987: Standard operating procedures for aerial waterfowl breeding ground population and habitat surveys in North America. U.S. Fish and Wildlife Service and Canadian Wildlife Service, $108 \mathrm{pp}$.

van der Schrier, G., J. Barichivich, K. R. Briffa, and P. D. Jones, 2013: A scPDSI-based global data set of dry and wet spells for 1901-2009. J. Geophys. Res., 118, 4025-4028, doi:10.1002/ jgrd.50355.

Vecchia, A. V., 2008: Climate simulation and flood risk analysis for 2008-40 for Devil's Lake, North Dakota. U.S. Geologic Survey Scientific Investigations Rep. 2008-5011, 30 pp.

Earth Interactions is published jointly by the American Meteorological Society, the American Geophysical Union, and the Association of American Geographers. Permission to use figures, tables, and brief excerpts from this journal in scientific and educational works is hereby granted provided that the source is acknowledged. Any use of material in this journal that is determined to be "fair use" under Section 107 or that satisfies the conditions specified in Section 108 of the U.S. Copyright Law (17 USC, as revised by P.IL. 94553) does not require the publishers' permission. For permission for any other from of copying, contact one of the copublishing societies. 